\title{
Efeito de época de poda, cianamida hidrogenada e irrigação na produção antecipada de figos verdes ${ }^{(1)}$
}

\author{
Paulo Márcio Norberto ${ }^{(2)}$, Nilton Nagib Jorge Chalfun(2), Moacir Pasqual(2), Ruben Delly Veiga( ${ }^{(3)}$ e José Hortêncio Mota ${ }^{(2)}$
}

\begin{abstract}
Resumo - O objetivo deste trabalho foi avaliar o efeito de época de poda, aplicação de cianamida hidrogenada (Dormex) e de irrigação no desenvolvimento da figueira (Ficus carica L.) cultivar Roxo de Valinhos e na produção antecipada de frutos verdes para indústria. Os tratamentos constaram de: dez épocas de poda, com intervalos de 15 dias; aplicação de solução a $2 \%$ de cianamida hidrogenada; aplicação de cianamida hidrogenada + irrigação; e irrigação três vezes por semana, fornecendo $40 \mathrm{~L}$ de água/planta/dia. As plantas podadas na segunda quinzena de maio, irrigadas, e que receberam cianamida hidrogenada, apresentaram maior número médio de frutos, e maior comprimento dos ramos, e produziram frutos na entressafra (outubro); nas podas mais precoces (primeira quinzena de abril até a segunda quinzena de maio) houve um prolongamento no ciclo das plantas, embora a primeira quinzena de abril tenha possibilitado a colheita de figos na entressafra; nas épocas de poda mais tardias (primeira quinzena de junho até a segunda quinzena de agosto), os tratamentos cianamida hidrogenada + irrigação, e somente irrigação, apresentaram maior comprimento de ramo e maior número de frutos, mas as colheitas foram iniciadas no período normal da safra.
\end{abstract}

Termos para indexação: Ficus carica, época de colheita, rendimento de cultura.

\section{Effect of pruning time, hydrogenated cyanamide and irrigation upon anticipated production of green figs}

\begin{abstract}
The objective of this work was to evaluate the effect of the pruning time, the application of hydrogenated cyanamide (Dormex), and of the irrigation on plant development and on the premature production of green figs (Ficus carica L.), cultivar Roxo de Valinhos, for the industry. Treatments consisted of ten pruning times, with intervals of 15 days, application of the solution at $2 \%$ of hydrogenated cyanamide, application of hydrogenated cyanamide + irrigation, and irrigation three times a week, supplying $40 \mathrm{~L}$ of water/plant/day. The pruned plants at the May's second fortnight, which were irrigated and received hydrogenated cyanamide, presented a larger number of fruits as average, larger branch length, and produced off-season fruits (October); into more precocious prunings (from April's first fortnight to May's first fortnight) there was a prolongation in the plant cycle, although the April's first fortnight had facilitated the off-season fig crops; in the later pruning times (from June's first fortnight to August's second fortnight) the treatments referred to hydrogenated cyanamide + irrigation, and irrigation, presented a larger length of branch and larger number of fruits, but the crops were initiated at the normal period of the crop.
\end{abstract}

Index terms: Ficus carica, harvesting date, crop yield.

(1)Aceito para publicação em 20 de outubro de 2000 .

Extraído da Dissertação de Mestrado apresentada pelo primeiro autor à Universidade Federal de Lavras (Ufla), Lavras, MG.

(2) Ufla, Dep. de Agricultura, Caixa Postal 37, CEP 37200-000 Lavras, MG. E-mail: metale@ufla.br, josehort@ufla.br

(3) Ufla, Dep. de Ciências Exatas. E-mail: idelly@ufla.br

\section{Introdução}

A figueira (Ficus carica L.), planta de clima temperado, requer poda hibernal que geralmente é realizada no final do inverno (julho/agosto), próximo à época da brotação, uma vez que a produção é obtida nos ramos novos, ou do ano, emitidos no mesmo ciclo. Assim sendo, promove-se a eliminação quase 
que total da copa formada no ciclo anterior, onde os ramos são reduzidos a $5-10 \mathrm{~cm}$, de forma a ficarem com pelo menos duas gemas em suas extremidades voltadas para fora da planta para formação da nova copa (Chalfun et al., 1998).

A época de poda pode variar, de maio a novembro, com o objetivo de acelerar ou retardar a época da colheita, respectivamente, conforme as condições climáticas e o desenvolvimento da planta (Chalfun et al., 1998). A planta podada nestes períodos poderá ter sua produtividade afetada, podendo, porém, apresentar vantagens econômicas. Santos (1994) relata que a poda antecipada na região de Valinhos predispõe a figueira a geadas tardias. Contudo, em regiões de inverno ameno, como é o caso de Lavras, a poda realizada mais cedo pode resultar em colheitas antecipadas, possibilitando a oferta de figo na entressafra e proporcionando melhores preços.

A prática da poda parece atuar como estímulo à quebra da dormência, uma vez que os ferimentos causados nos tecidos geram estímulos de crescimento nas células cambiais e dos meristemas (Samish, 1954). Pereira \& Lopes (1979), estudando o efeito da calcionamida sobre a brotação e desenvolvimento dos brotos de figueira, cultivar Roxo de Valinhos, verificaram que quando aplicada a concentração de $20 \%$ após a poda realizada em junho, acelerou o desenvolvimento inicial dos brotos, tornando possível, naquela região, a produção de frutos mais cedo, pela sua antecipação, sem que ocorram falhas na brotação e com desenvolvimento adequado de ramos. Ollita et al. (1979), utilizando o sistema de irrigação por gotejo, em figueiras da cultivar Roxo de Valinhos, em duas freqüências de irrigação e aplicação de três quantidades de água, observaram que a irrigação com freqüência de uma semana e com volume de água equivalente a $\mathrm{K}=0,4$ da evaporação do tanque classe A permitiu ampliar e antecipar o período produtivo, aumentando em 14,6\% o número de frutos e em 19,4\% o seu peso médio em relação às plantas que não foram irrigadas.

Brighenti (1980), com a irrigação por sulcos em figueira 'Roxo de Valinhos', obteve aumento de $21,3 \%$ no número de frutos, $30,5 \%$ no seu peso total, e $19,4 \%$ no peso médio das plantas mantidas sob um regime mínimo de $60 \%$ de água disponível, em relação às que não foram irrigadas.
O objetivo deste trabalho foi verificar o efeito da época de poda, da aplicação da cianamida hidrogenada, e da irrigação, no desenvolvimento e produção de figos verdes na região de Lavras, MG.

\section{Material e Métodos}

O experimento foi realizado em área do setor de fruticultura da Universidade Federal de Lavras, MG, no período de abril de 1997 a maio de 1998. O solo da área do experimento é um Latossolo Vermelho-Escuro, textura argilo-arenosa.

A cultivar de figueira utilizada foi a Roxo de Valinhos, com cinco anos de idade, plantadas no espaçamento $2,5 \times 1,5 \mathrm{~m}$.

O delineamento experimental utilizado foi inteiramente casualizado, disposto em esquema fatorial $10 \times 4$, envolvendo dez épocas de poda e quatro tratamentos, que consistiram na aplicação de cianamida hidrogenada, cianamida hidrogenada + irrigação, irrigação, e a testemunha, com três repetições e uma planta por parcela. As plantas foram podadas quinzenalmente, de abril a agosto de 1997. O sistema de poda utilizado foi o de poda drástica, na qual são eliminados todos os ramos formados no ciclo anterior, deixando-se apenas três "pernadas" por planta, medindo $15 \mathrm{~cm}$ cada.

A pulverização da solução de cianamida hidrogenada a $2 \%$ foi efetuada logo após a poda, com auxílio de pulverizador costal, e o produto foi aplicado nas três pernadas da planta, bem como no tronco até o ponto de escorrimento, conforme o tratamento.

Os dados meteorológicos registrados durante a condução do experimento são apresentados na Tabela 1.

A irrigação foi efetuada com uso de regadores manuais sem crivo, três vezes por semana, fornecendo $20 \mathrm{~L}$ de água pela manhã e $20 \mathrm{~L}$ à tarde por planta. "Bacias" foram construídas junto às plantas que receberam este tratamento. As plantas foram conduzidas pelo sistema de desponte, e os tratos culturais e fitossanitários foram executados ao longo da condução do experimento, de acordo com a necessidade da cultura. As características avaliadas foram: número médio de frutos, obtido mediante a contagem dos frutos em cada dois ramos marcados por parcela, por ocasião da primeira colheita; comprimento médio dos ramos, obtido através da medição de dois ramos marcados por planta, por ocasião da primeira colheita; produção da primeira colheita ( $\mathrm{kg} /$ planta), obtida nos seis ramos iniciais conduzidos por planta, que teve início quando pelo menos $80 \%$ dos frutos se apresentavam com a característica de firmeza e produção total ( $\mathrm{kg} /$ planta), obtida pelo somatório de quatro colheitas. 


\section{Resultados e Discussão}

O maior número de frutos por ramo foi obtido na poda realizada em 15 de abril, e o menor, em 30 de abril, no tratamento com cianamida hidrogenada (Tabela 2).

No tratamento cianamida hidrogenada + irrigação, a poda realizada em 30 de maio apresentou, em média, 13,33 frutos/ramo, com isso se destacando das demais épocas de poda, o que também ocorreu nos tratamentos de 15 de julho, 30 de julho e 15 de maio. Neste contexto, Maraschin et al. (1992), em trabalhos com videira (Niágara Branca), relataram que a utilização de reguladores de crescimento tem-se mostrado eficiente no sentido de quebrar a dormência das gemas, antecipando-as e proporcionando maior uniformidade de brotações, bem como elevando os valores de produção. Quando as plantas foram apenas irrigadas, verificou-se que os menores números de frutos por ramo foram obtidos nas podas realizadas em 30 de abril e 30 de junho, e as demais épocas de poda não diferiram entre si. Portanto, fica evidente que a irrigação promoveu tanto o aumento no número de frutos/ramo como possibilitou a antecipação da colheita em épocas de poda precoces (15 de abril a 30 de maio) (Tabela 3). Resultados semelhantes foram obtidos por Ollita et al. (1979), que, utili- zando o sistema de irrigação por gotejo em figueira, cultivar Roxo de Valinhos, ampliaram e anteciparam o período produtivo, aumentando em 14,6\% o número de frutos, e em $19,4 \%$, o seu peso médio. A testemunha obteve os melhores resultados quando sua poda foi realizada em 30 de junho, com 11,83 frutos em média, por ramo, e os menores resultados foram verificados nas épocas de poda mais precoce.

A variabilidade existente entre os valores dos índices de número médio de frutos encontrados devese, provavelmente, à época de aplicação da cianamida hidrogenada, bem como às condições climáticas peculiares de cada época, uma vez que não se encontram elucidados os efeitos isolados e combinados que a época de poda, a cianamida hidrogenada e a irrigação podem exercer sobre a produção da figueira.

A poda realizada em 15 de abril propiciou o maior número de frutos/ramo nas plantas que receberam apenas cianamida hidrogenada, sem diferir do tratamento irrigação isolado. Já em 15 de maio, o melhor resultado foi verificado no tratamento cianamida hidrogenada + irrigação, valor similar ao da irrigação (Tabela 2).

Apesar de os resultados obtidos nos tratamentos supra mencionados serem considerados satis-

Tabela 1. Dados meteorológicos registrados no período de abril/1997 a maio/1998 na Estação Climatológica principal de Lavras, MG, situada no Campus da Ufla.

\begin{tabular}{|c|c|c|c|c|c|}
\hline \multirow[t]{2}{*}{ Mês } & \multicolumn{3}{|c|}{ Temperatura $\left({ }^{\circ} \mathrm{C}\right)$} & \multirow{2}{*}{$\begin{array}{l}\text { Umidade } \\
\text { relativa }(\%)\end{array}$} & \multirow{2}{*}{$\begin{array}{l}\text { Precipitação } \\
\text { pluvial (mm) }\end{array}$} \\
\hline & Máxima & Mínima & Média & & \\
\hline Abril/97 & 30,2 & 11,5 & 19,9 & 75 & 199,9 \\
\hline Maio/97 & 28,7 & 8,6 & 17,6 & 75 & 38,0 \\
\hline Junho/97 & 28,9 & 3,5 & 16,5 & 68 & 51,0 \\
\hline Julho/97 & 28,3 & 8,0 & 17,4 & 67 & 5,6 \\
\hline Agosto/97 & 31,6 & 6,0 & 18,5 & 55 & 1,2 \\
\hline Setembro/97 & 35,2 & 12,2 & 21,7 & 67 & 38,8 \\
\hline Outubro/97 & 35,0 & 12,1 & 22,2 & 65 & 91,1 \\
\hline Novembro/97 & 34,4 & 16,1 & 23,4 & 73 & 194,8 \\
\hline Dezembro/97 & 28,4 & 18,8 & 23,0 & 78 & 253,6 \\
\hline Janeiro/98 & 29,6 & 18,9 & 23,4 & 78 & 149,5 \\
\hline Fevereiro/98 & 30,1 & 19,3 & 23,7 & 78 & 159,2 \\
\hline Março/98 & 29,9 & 18,5 & 22,6 & 77 & 140,1 \\
\hline Abril/98 & 28,0 & 16,9 & 21,4 & 74 & 32,6 \\
\hline Maio/98 & 24,9 & 13,0 & 18,0 & 72 & 73,7 \\
\hline
\end{tabular}


Tabela 2. Número médio de frutos/ramo, comprimento médio dos ramos, produção da primeira colheita e produção total de figueira 'Roxo de Valinhos' em resposta aos tratamentos utilizados em diferentes épocas da poda. Ufla, Lavras, MG, 1999(1)

\begin{tabular}{|c|c|c|c|c|}
\hline Época de poda & $\begin{array}{c}\text { Cianamida } \\
\text { hidrogenada }\end{array}$ & $\underset{\text { irrigação }}{\text { Cianam. hidrog. }+}$ & Irrigação & Testemunha \\
\hline & \multicolumn{4}{|c|}{ Número médio de frutos/ramo } \\
\hline 15 de abril & $12,67 \mathrm{aA}$ & $11,00 \mathrm{bBCD}$ & $10,50 \mathrm{aAB}$ & $8,00 \mathrm{cDE}$ \\
\hline 30 de abril & $7,17 \mathrm{abC}$ & $8,00 \mathrm{aE}$ & $7,83 \mathrm{aC}$ & $6,00 \mathrm{bF}$ \\
\hline 15 de maio & $10,17 \mathrm{bB}$ & $11,83 \mathrm{aABC}$ & $11,17 \mathrm{abA}$ & $10,17 \mathrm{bABC}$ \\
\hline 30 de maio & $10,17 \mathrm{bB}$ & $13,33 \mathrm{aA}$ & $11,00 \mathrm{bA}$ & $7,00 \mathrm{cEF}$ \\
\hline 15 de junho & $9,17 \mathrm{bB}$ & $10,83 \mathrm{aBCD}$ & $11,50 \mathrm{aA}$ & $11,00 \mathrm{aAB}$ \\
\hline 30 de junho & $9,33 \mathrm{bB}$ & $9,50 \mathrm{bDE}$ & $9,00 \mathrm{bBC}$ & $11,83 \mathrm{aA}$ \\
\hline 15 de julho & $10,67 \mathrm{bB}$ & $12,50 \mathrm{aAB}$ & $12,17 \mathrm{aA}$ & $9,00 \mathrm{cCD}$ \\
\hline 30 de julho & $10,83 \mathrm{abB}$ & $12,17 \mathrm{aAB}$ & $11,33 \mathrm{abA}$ & $10,33 \mathrm{bABC}$ \\
\hline 15 de agosto & $9,67 \mathrm{bB}$ & $10,17 \mathrm{abCD}$ & $11,33 \mathrm{aA}$ & $11,00 \mathrm{abAB}$ \\
\hline \multirow[t]{2}{*}{30 de agosto } & $10,83 \mathrm{abB}$ & $10,83 \mathrm{abBCD}$ & $11,50 \mathrm{aA}$ & $9,83 \mathrm{bBC}$ \\
\hline & \multicolumn{4}{|c|}{ Comprimento médio dos ramos $(\mathrm{cm})$} \\
\hline 15 de abril & $75,40 \mathrm{aA}$ & $71,67 \mathrm{aBCD}$ & $74,50 \mathrm{aAB}$ & $52,00 \mathrm{bBC}$ \\
\hline 30 de abril & $66,00 \mathrm{abABC}$ & $77,33 \mathrm{aABC}$ & $75,00 \mathrm{aAB}$ & $58,83 \mathrm{bABC}$ \\
\hline 15 de maio & $62,17 \mathrm{abABCD}$ & $72,50 \mathrm{aBCD}$ & $63,67 \mathrm{abBC}$ & $49,50 \mathrm{bCD}$ \\
\hline 30 de maio & $63,83 \mathrm{bABC}$ & $86,50 \mathrm{aAB}$ & $67,50 \mathrm{bBC}$ & $51,50 \mathrm{cBCD}$ \\
\hline 15 de junho & $56,60 \mathrm{cBCD}$ & $82,00 \mathrm{aAB}$ & $73,83 \mathrm{abAB}$ & $62,17 \mathrm{bcAB}$ \\
\hline 30 de junho & $59,50 \mathrm{bABCD}$ & $81,33 \mathrm{aAB}$ & $76,50 \mathrm{aAB}$ & $58,33 \mathrm{bABC}$ \\
\hline 15 de julho & $70,00 \mathrm{cAB}$ & $91,33 \mathrm{aA}$ & $89,17 \mathrm{abA}$ & $76,50 \mathrm{bcA}$ \\
\hline 30 de julho & $65,83 \mathrm{aABC}$ & $77,67 \mathrm{aABC}$ & $73,33 \mathrm{aAB}$ & $64,17 \mathrm{aAB}$ \\
\hline 15 de agosto & $65,50 \mathrm{abABC}$ & $78,50 \mathrm{aABC}$ & $71,83 \mathrm{abAB}$ & $59,00 \mathrm{bABC}$ \\
\hline \multirow{2}{*}{30 de agosto } & $67,67 \mathrm{aABC}$ & $78,67 \mathrm{aABC}$ & $81,66 \mathrm{aAB}$ & $71,16 \mathrm{aAB}$ \\
\hline & \multicolumn{4}{|c|}{ Produção da primeira colheita } \\
\hline 15 de abril & $1,080 \mathrm{aA}$ & $0,990 \mathrm{aBC}$ & $0,900 \mathrm{abAB}$ & $0,720 \mathrm{bBC}$ \\
\hline 30 de abril & $0,630 \mathrm{aB}$ & $0,720 \mathrm{aC}$ & $0,680 \mathrm{aB}$ & $0,540 \mathrm{aC}$ \\
\hline 15 de maio & $0,900 \mathrm{aAB}$ & $0,990 \mathrm{aBC}$ & $1,004 \mathrm{aA}$ & $0,814 \mathrm{aABC}$ \\
\hline 30 de maio & $0,918 \mathrm{bAB}$ & $1,699 \mathrm{aA}$ & $0,995 \mathrm{bA}$ & $0,630 \mathrm{cC}$ \\
\hline 15 de junho & $0,824 \mathrm{aAB}$ & $0,974 \mathrm{aBC}$ & $1,035 \mathrm{aA}$ & $0,990 \mathrm{aAB}$ \\
\hline 30 de junho & $0,839 \mathrm{abAB}$ & $0,855 \mathrm{abBC}$ & $0,810 \mathrm{bAB}$ & $1,060 \mathrm{aA}$ \\
\hline 15 de julho & $0,820 \mathrm{bAB}$ & $1,125 \mathrm{aB}$ & $1,100 \mathrm{aA}$ & $0,980 \mathrm{abA}$ \\
\hline 30 de julho & $0,879 \mathrm{aAB}$ & $1,097 \mathrm{aB}$ & $1,030 \mathrm{aA}$ & $0,900 \mathrm{aAB}$ \\
\hline 15 de agosto & $0,869 \mathrm{aAB}$ & $0,930 \mathrm{aBC}$ & $1,025 \mathrm{aA}$ & $0,990 \mathrm{aAB}$ \\
\hline \multirow[t]{2}{*}{30 de agosto } & $0,900 \mathrm{aAB}$ & $1,010 \mathrm{aBC}$ & $1,040 \mathrm{aA}$ & $0,995 \mathrm{aAB}$ \\
\hline & \multicolumn{4}{|c|}{ Produção total (kg/planta) } \\
\hline 15 de abril & $3,334 \mathrm{aE}$ & $2,877 \mathrm{bF}$ & $2,716 \mathrm{bF}$ & $2,300 \mathrm{bE}$ \\
\hline 30 de abril & $3,224 \mathrm{bE}$ & $3,471 \mathrm{aE}$ & $3,485 \mathrm{aC}$ & $2,420 \mathrm{cE}$ \\
\hline 15 de maio & $3,593 \mathrm{cD}$ & $4,148 \mathrm{aD}$ & $3,867 \mathrm{bB}$ & $3,000 \mathrm{dC}$ \\
\hline 30 de maio & $4,367 \mathrm{bB}$ & $6,543 \mathrm{aA}$ & $3,228 \mathrm{cD}$ & $2,950 \mathrm{dC}$ \\
\hline 15 de junho & $1,466 \mathrm{dH}$ & $1,953 \mathrm{cH}$ & $2,950 \mathrm{aE}$ & $2,345 \mathrm{bE}$ \\
\hline 30 de junho & $3,091 \mathrm{dF}$ & $4,661 \mathrm{aC}$ & $3,952 \mathrm{bB}$ & $3,550 \mathrm{cB}$ \\
\hline 15 de julho & $1,969 \mathrm{cG}$ & $4,909 \mathrm{aB}$ & $4,916 \mathrm{aA}$ & $3,789 \mathrm{bA}$ \\
\hline 30 de julho & $3,090 \mathrm{bF}$ & $4,625 \mathrm{aC}$ & $3,167 \mathrm{bD}$ & $2,799 \mathrm{cD}$ \\
\hline 15 de agosto & $5,144 \mathrm{aA}$ & $4,666 \mathrm{cC}$ & $4,881 \mathrm{bA}$ & $3,015 \mathrm{dC}$ \\
\hline 30 de agosto & $3,866 \mathrm{aC}$ & $2,334 \mathrm{dG}$ & $3,251 \mathrm{bD}$ & $2,717 \mathrm{cD}$ \\
\hline
\end{tabular}


fatórios, segundo Santos (1997), as três primeiras épocas de poda prolongaram muito o período vegetativo das plantas, retardando, desse modo, o início da primeira colheita (Tabela 3). Embora as plantas podadas em 15 de abril tenham possibilitado o início da colheita em 12 de outubro, ou seja, dentro do período de entressafra, conforme Antunes et al.

Tabela 3. Data da primeira colheita e período entre poda e colheita referente à safra 1997/98, em resposta à época da poda e aos tratamentos em figueira 'Roxo de Valinhos', Ufla, Lavras, MG, 1999.

\begin{tabular}{|c|c|c|c|}
\hline $\begin{array}{l}\text { Época } \\
\text { de poda }\end{array}$ & Tratamento & $\begin{array}{l}\text { Data da } 1^{\mathrm{a}} \\
\text { colheita }\end{array}$ & $\begin{array}{c}\text { Período entre } \\
\text { poda e colheita } \\
\text { (dias) }\end{array}$ \\
\hline \multirow[t]{4}{*}{$15 / 4$} & Cianamida & $12 / 10$ & 181 \\
\hline & Cianamida + irrigação & $12 / 10$ & 181 \\
\hline & Irrigação & $17 / 10$ & 186 \\
\hline & Testemunha & $23 / 10$ & 192 \\
\hline \multirow[t]{4}{*}{$30 / 4$} & Cianamida & $1 / 11$ & 186 \\
\hline & Cianamida + irrigação & $1 / 11$ & 186 \\
\hline & Irrigação & $1 / 11$ & 186 \\
\hline & Testemunha & $5 / 11$ & 190 \\
\hline \multirow[t]{4}{*}{$15 / 5$} & Cianamida & $11 / 11$ & 181 \\
\hline & Cianamida + irrigação & $11 / 11$ & 181 \\
\hline & Irrigação & $11 / 11$ & 181 \\
\hline & Testemunha & $16 / 11$ & 186 \\
\hline \multirow[t]{4}{*}{$30 / 5$} & Cianamida & $22 / 10$ & 146 \\
\hline & Cianamida + irrigação & $7 / 10$ & 131 \\
\hline & Irrigação & $27 / 10$ & 151 \\
\hline & Testemunha & $6 / 11$ & 161 \\
\hline \multirow[t]{4}{*}{$15 / 6$} & Cianamida & $27 / 11$ & 166 \\
\hline & Cianamida + irrigação & $17 / 11$ & 156 \\
\hline & Irrigação & $27 / 11$ & 166 \\
\hline & Testemunha & $2 / 12$ & 171 \\
\hline \multirow[t]{4}{*}{$30 / 6$} & Cianamida & $28 / 11$ & 152 \\
\hline & Cianamida + irrigação & $28 / 11$ & 152 \\
\hline & Irrigação & $2 / 12$ & 156 \\
\hline & Testemunha & $12 / 12$ & 166 \\
\hline \multirow[t]{4}{*}{$15 / 7$} & Cianamida & $18 / 12$ & 157 \\
\hline & Cianamida + irrigação & $18 / 12$ & 157 \\
\hline & Irrigação & $18 / 12$ & 157 \\
\hline & Testemunha & $23 / 12$ & 162 \\
\hline \multirow[t]{4}{*}{$30 / 7$} & Cianamida & $22 / 12$ & 146 \\
\hline & Cianamida + irrigação & $22 / 12$ & 146 \\
\hline & Irrigação & $22 / 12$ & 146 \\
\hline & Testemunha & $27 / 12$ & 151 \\
\hline \multirow[t]{4}{*}{$15 / 8$} & Cianamida & $8 / 1$ & 147 \\
\hline & Cianamida + irrigação & $3 / 1$ & 142 \\
\hline & Irrigação & $8 / 1$ & 147 \\
\hline & Testemunha & $13 / 1$ & 152 \\
\hline \multirow[t]{4}{*}{$30 / 8$} & Cianamida & $22 / 1$ & 146 \\
\hline & Cianamida + irrigação & $22 / 1$ & 146 \\
\hline & Irrigação & $22 / 1$ & 146 \\
\hline & Testemunha & $27 / 1$ & 151 \\
\hline
\end{tabular}

(1997), o ciclo dessas plantas foi superior a 6 meses, enquanto o intervalo normal entre a poda de inverno da figueira e o início da colheita é de 4 a 5 meses.

Passos \& Trintin (1982) observaram um prolongamento na duração do ciclo vegetativo das videiras quando foram podadas precocemente. O prolongamento do período vegetativo das plantas podadas nas três primeiras épocas não foi observado nas plantas podadas em 30 de maio, que propiciaram o início da primeira colheita em 7/10 (Tabela 3), ou seja, justamente no início do período de entressafra, conseguindo-se uma antecipação de aproximadamente dois meses em relação à época normal da colheita.

A colheita das plantas que foram podadas de 15 de junho até 30 de agosto foi iniciada dentro do período normal de safra, ou seja, em dezembro e janeiro, quando a oferta de figos verdes é bem maior que a procura, isto é, fora da época das melhores cotações de preço no mercado (Antunes et al., 1997).

Quanto às médias dos comprimentos dos ramos, a cianamida hidrogenada aumentou significativamente o desenvolvimento dos ramos independentemente da época de poda, porém, o melhor resultado foi verificado na poda realizada em 15 de abril (Tabela 2). Esses resultados concordam com os obtidos por Mattioda et al. (1987), em videira, na qual avaliaram o efeito da aplicação de cianamida hidrogenada em doses que variaram de $0 \%$ a $10 \%$, em diferentes cultivares, em três épocas de podas, e verificaram que a cianamida hidrogenada aumentou e uniformizou a porcentagem de brotação e crescimento dos ramos, bem como a produtividade dessas plantas. Pires (1995) verificou também que os tratamentos com cianamida hidrogenada, independentemente das doses aplicadas, quebraram a dormência das gemas e promoveram o pleno desenvolvimento dos ramos de videiras cultivar Niágara Rosada.

As plantas que receberam o tratamento cianamida hidrogenada + irrigação em todas as épocas de poda testadas foram as que apresentaram valores de comprimento e uniformidade de ramos superiores aos obtidos pelas plantas que receberam os outros tratamentos (Tabela 2). Porém, o maior comprimento de ramo foi observado na poda realizada em 15 de julho, ou seja, mais próxima do final do inverno, que, com temperaturas mais elevadas, promove a redu- 
ção dos inibidores e favorece os promotores de crescimento, elevando, dessa maneira, a atividade respiratória da planta (Gardea et al., 1994). Os tratamentos que receberam apenas a irrigação foram mais eficientes em contribuir para um maior crescimento e maior uniformidade dos ramos, e o melhor resultado foi observado na poda realizada em 15 de julho. O melhor resultado de comprimento de ramo foi verificado quando as plantas foram podadas em 15 de julho; e o pior resultado, em 15 de maio, na testemunha, sendo que suas plantas foram apenas podadas dentro das respectivas épocas, sem nenhum tratamento adicional.

Como a época da colheita está estreitamente relacionada com a época da poda e com o clima, observa-se (Tabela 2) a eficiência da aplicação de cianamida hidrogenada, cianamida hidrogenada + irrigação, e da irrigação em uniformizar os ramos, possibilitando, assim, a oferta de figo fora da época normal de safra (Tabela 3). Resultados semelhantes foram observados por Pereira \& Lopes (1979), que, com aplicação de calcionamida (20\%) após a poda realizada em junho, aceleraram o desenvolvimento inicial dos brotos de figueiras cultivadas em Campinas, SP, tornando possível, naquela região, a produção de frutos mais cedo, sem falhas na brotação e com desenvolvimento adequado dos ramos, permitindo, assim, a obtenção de melhores preços pelo produto.

Quando a cianamida hidrogenada foi aplicada separadamente, a maior produção da primeira colheita foi obtida quando as plantas foram podadas em 15 de abril, e as plantas nas demais épocas de poda não diferiram estatisticamente entre si (Tabela 2). Já com o tratamento cianamida hidrogenada + irrigação, o melhor resultado foi verificado quando as plantas foram podadas em 30 de maio, diferindo estatisticamente dos demais tratamentos. Evidencia-se, assim, uma boa alternativa para obter quase $30 \%$ da produção total já no início do mês de outubro (Tabela 3), justamente no período de entressafra, no qual o preço do figo verde para indústria chega a $\mathrm{R} \$ 2,00 / \mathrm{kg}$ (Antunes et al., 1997). Esses resultados foram semelhantes aos obtidos por Pires (1995), que aumentou e antecipou a colheita de uva Niágara Rosada com a aplicação de cianamida hidrogenada. Com relação às podas realizadas em 15 de abril, 30 de abril e 15 de maio, constata-se que, embora tenham produzido no período de entressafra e próximo dele (Tabela 3), o ciclo dessas plantas, independentemente do tratamento que receberam, foi prolongado, ultrapassando seis meses, da poda até a primeira colheita.

Nas plantas que foram apenas irrigadas, percebese que, em quase a totalidade das épocas de poda, não houve diferença significativa na produção da primeira colheita de figo verde (Tabela 2). Na testemunha, as menores médias de produção da primeira colheita foram verificadas nas podas realizadas em 30 de abril e 30 de maio, e a maior produção em 30 de junho, o que evidencia que a produção diminuiu quando a época de poda foi antecipada. Este resultado está de acordo com os encontrados por Maraschin et al. (1992), em videira Niágara Branca, que verificaram que quando a época de poda foi antecipada houve acentuada diminuição na produção. Quanto às épocas de poda mais tardias, verificou-se uma sensível elevação nos valores de produção da primeira colheita, provavelmente causada pelo reequilíbrio hormonal das plantas após o período de dormência.

Quando a cianamida hidrogenada foi aplicada isoladamente, a maior produção foi obtida nas plantas podadas em 15 de agosto, e a menor, na poda realizada em 15 de junho. Do mesmo modo, Maraschin et al. (1992) observaram maior produção de uva Niágara Branca quando se faz uso de calcionamida (Tabela 2).

Quando a cianamida hidrogenada foi associada à irrigação, o melhor resultado foi obtido na poda realizada em 30 de maio, e o pior, em 15 de junho, mostrando, assim, comportamento semelhante ao do menor resultado do tratamento anterior. Dessa forma, fica claro que o emprego da cianamida hidrogenada + irrigação nas plantas podadas em 30 de maio aumentou significativamente a produção total, bem como aumentou e antecipou a produção da primeira colheita. Quanto às plantas que receberam apenas irrigação, os melhores resultados foram observados nas podas realizadas em 15 de julho e 15 de agosto, com produção de $4,916 \mathrm{~kg} \mathrm{e} 4,881 \mathrm{~kg}$, respectivamente, e a menor produção, $2,716 \mathrm{~kg}$, na poda de $15 \mathrm{de}$ abril. A testemunha mostrou que a melhor época, para efetuar a poda da figueira, é na primeira quinzena de julho, quando se verificou o melhor resultado de produção. 


\section{Conclusões}

1. As podas realizadas no período de $15 / 4$ a $15 / 5$, associadas à cianamida hidrogenada mais irrigação, aumentam em $28 \%$ o número de frutos e em $38 \%$ o comprimento de ramos.

2. A poda realizada em $30 / 5$ associada à cianamida hidrogenada mais irrigação proporciona, além da obtenção da primeira colheita no início da entressafra, uma produção inicial de $1,699 \mathrm{~kg} /$ planta e uma produção final de $6,543 \mathrm{~kg} /$ planta.

\section{Referências}

ANTUNES, L. E. C.; ABRAHÃO, E.; SILVA, V. J. Caracterização da cultura da figueira no Estado de Minas Gerais. Informe Agropecuário, Belo Horizonte, v. 18, n. 188 , p. 43-44, 1997.

BRIGHENTI, E. Influência do número de ramos básicos e da irrigação na produção de figos verdes (Ficus carica L.) da cultivar 'Roxo de Valinhos'. Pelotas: Ufpel, 1980. 48 p. Dissertação de Mestrado.

CHALFUN, N. N. J.; HOFFMANN, A.; PASQUAL, M. Frutíferas de clima temperado. Lavras: Ufla/Faepe, 1998. v. 7.

GARDEA, A. A.; MORENO, Y. M.; AZARENKO, A. N.; LOMBARD, P. B.; DALEY, L. S.; CRIDDLE, R. S. Changes in metabolic properties of grapebud during development. Journal of the American Society for Horticultural Science, Alexandria. v. 119, n. 4, p. 756760, 1994.

MARASCHIN, M.; KOLLER, O. C.; SILVA, A. L. Efeito da época de poda e calcionamida na quebra de dormência e produtividade da videira cv. Niágara Branca, no Litoral catarinense. Pesquisa Agropecuária Brasileira, Brasília, v. 27, n. 3, p. 455-462, mar. 1992.
MATTIODA, H.; FEVRE, F.; DUMARTIN, P.; PAYAN, J. J. Utilisation du SKW (Cyanamid hydrogenée) pour l'amélioration du débourrement de la vigne en France. In: SYMPOSIUM INTERNATIONAL SUR LA PHYSIOLOGIE DE LA VIGNE, 3., Bordeaux, 1986. Comptés Rendues. Paris: Office International de la Vigne et du Vin, 1987. p. 61-67.

OLLITA, A. F.; SAMPAIO, V. R.; BARBIN, D. Estudo da lâmina e freqüência de irrigação por gotejo na cultura do figo. O Solo, Piracicaba, v. 11, n. 2, p. 9-22, 1979.

PASSOS, L. P.; TRINTIN, P. L. Resposta da videira à variação da época de poda seca: III. Efeitos no comportamento fenológico da cv. Isabel. Bento Gonçalves: Embrapa-Uepae, 1982. 6 p. (Pesquisa em Andamento, 3).

PEREIRA, F. M.; LOPES, J. A. Efeitos da calcionamida e da uréia sobre a brotação da figueira (Ficus carica L.) cultivar Roxo de Valinhos. In: CONGRESSO BRASILEIRO DE FRUTICULTURA, 5., Pelotas, 1979. Anais... Pelotas : Sociedade Brasileira de Fruticultura, 1979. p. 128-135.

PIRES, J. P. Estudo de compostos químicos na quebra de dormência das gemas, na brotação e na produtividade da videira cultivar 'Niágara Rosada' nas principais regiões produtoras do Estado de São Paulo. Piracicaba: Esalq, 1995. 95 p. Tese de Doutorado.

SAMISH, R. M. Dormancy in woody plants. Annual Review of Plant Physiology, Palo Alto, v. 5, p. 183-204, 1954

SANTOS, S. C. Efeitos da época de poda e do número de ramos sobre o desenvolvimento, produção e rentabilidade da figueira (Ficus carica L.), cultivada em Selvíria-MS. Ilha Solteira: Unesp, 1997. 67 p. Dissertação de Mestrado.

SANTOS, S. C. Efeitos de épocas de poda sobre a produção e qualidade dos frutos da figueira (Ficus carica L.), cultivada em Selvíria-MS. Ilha Solteira: Unesp, 1994. 50 p. 